\title{
FUZZY LOGIC APPROACH FOR THE DESIGN OF REINFORCEMENT IN TUNNEL EXCAVATION
}

\author{
C. Y. Kim*, S. W. Hong, G. J. Bae, K. Y. Kim \\ Geotechnical Engineering Research Dept., \\ Korea Institute of Construction Technology (KICT), Korea \\ cykim@kict.re.kr
}

\begin{abstract}
Specification of reinforcement method was suggested according to the ground condition and tunnelling environment such as adjacent building and surface settlement. Tunnel database consists of 8 different groups of data according to the tunnel construction situations and major problems of ground. A tunnel countermeasure expert system based on client/server system was developed with on-line. The expert system provides proper solution to the each construction sites backing up the information of the tunnelling and ground information through Internet. The effective factors of tunnel construction were shown by the analyzing relationship and partial relationship between face stability and RMR factors. This study will be very helpful to make the most of in-situ data and suggest proper applicability of tunnel reinforcement system escaping from the dependence of some experienced experts for the absent of guide.
\end{abstract}

Keywords: tunnel failure, countermeasure, fuzzy quantification II theory, tunnel reinforcement design.

\section{INTRODUCTION}

Many studies of tunnel and tunnelling safety have been done based on the increasing social interests in underground space since 1990's in Korea. Increasing the construction of tunnel, it is important to define the cause of the abnormal phenomenon and then to carry out the countermeasure against the major cause. Especially, proper countermeasure for the unexpected and difficult excavation is urgently needed in the case of tunnelling site constructed in urban area. Although technological development of tunnel engineering has been accelerated consistently, there has been no clear specification of reinforcement method for the unstable tunnel situation in Korea.

In this study, a lot of types of tunnel failure and their countermeasure methods were surveyed, then the specification of countermeasure was suggested according to the ground condition and tunnelling environment such as adjacent building and surface settlement. A tunnel countermeasure expert system based on client/server system was developed with online database. The expert system provides proper solution to the each construction sites backing up the information of the tunnelling and ground information by internet.

This study will be very helpful to make the most of in-situ data and suggest proper applicability of tunnel reinforcement system escaping from the dependence of some experienced experts for the absent of guide.

\section{Modified Takagi-Sugeno (TS) Fuzzy Model}

On actual sites, the engineers often have to begin to cope with the safety problem while the cause is still unknown. However, the selection of counter measure is not easy because there are many unexpected problems and uncertainties of ground. In this study, many types of tunnel failure were surveyed and the detail causes were studied for brief countermeasure. Then, the expert system using fuzzy inference rule was developed (Chikahisa et al.1997).

The record of Tunnel failure and collapse throughout Korea has been established and 21 significant incidents are documented in this study. Especially, subway tunnels including second stage of Seoul subway, road tunnels and express railway tunnels have been analyzed. This data shows that these incidents, particularly in soft ground in urban areas, may, when they occur, result in major consequences not just to those working in the tunnel but to members of the public, the infrastructure and the built environment.

The 10 significant collapses and outlines of the circumstances of the incident were investigated during second stage of Seoul subway, and 11 major collapse incidents among the various tunnel sites were studied since 1993. Among those 21 incidents, 8 sites were surface collapse and large collapses more than $50 \mathrm{~m} 2$ were 5 cases. 14 incidents were occurred in urban areas and three in road tunnel and one in express railway tunnel (Kim et al. 2000).

Kim et al. (2000) analyzed the main cause factors of the collapsed tunnel analyzing the relationship between collapsed cases and their ground conditions. Especially, RMR classification items suggested by Bieniawski were considered because it is usually applied in-situ site of Korea. 20 significant incident sites are separated from 52 tunnel failure data and studied about water inflow, depth, rock type, joint, 
alteration and so on. Abroad failure tunnels surveyed by Cecil (1963), whose total length is approximately $67 \mathrm{~km}$ and which contain 14 projects and 97 sections are analyzed as well.

\section{Expert System for Tunnel Reinforcement}

According to the record of tunnel incidents above, proper countermeasure system is urgently needed so that the expert system was studied to predict the safety of tunnel and choose proper tunnel reinforcement method using fuzzy quantification theory and fuzzy inference rule based on tunnel information database (Watada et al. 1982). Using fuzzy theory, fuzzy membership function is composed and tunnel safety level is inferred through the membership function. After the tunnel safety level is graded, proper tunnel reinforcement is selected. This expert system is purposed to help the engineers to make a decision of counter measure against unexpected situation providing proper judgment criteria applying the fuzzy theory. Each observed items and tunnel face mapping data are changed to fuzzy set and tunnel reinforcement applicability has been inferred. To establish the membership function is the most important and difficult part of fuzzy inference system because of the absence of experienced engineers and lack of data. Quantification theory was used for building membership function as an alternative method (Kim et al. 2000). The membership function consists of more objective data through the application of quantification theory, which gives weight value to tunnel quality data. Tunnel safety set to be the independent criterion and the items of tunnel information database set to the subordinate variables and then, the fuzzy inference rule is predicted.

\subsection{Overview Fuzzy inference system}

Fuzzy sets were introduced by Zadeh as an approach to handling vagueness or uncertainty and, in particular, linguistic variables. Classical set theory allows for an object to be either a member of the set or excluded from the set. This, in many applications, is unsatisfactory since, for example, if one has the set that describes all males who are tall as those whose height is greater than $5^{\prime} 8$ " then a $60^{\prime \prime}$ male is a member of the set. A male whose height is 5'7 ", however, is not a member of the set. This implies that a man who is " shorter than another tall man is not tall.

By the same token this approach does not differentiate between members. Michael Jordan (6'8") and Bob John (5'11") are both equally members of the set 'tall'. Although this appears at face value to be a trivial example there are many domains where this approach is of little use. Fuzzy sets differ from classical sets in that they allow for an object to be a partial member of a set. So, for example, John may be a member of the set 'tall' to degree 0.8. He is tall to degree 0.8. Fuzzy sets are defined by a membership function. For any fuzzy set A the function represent the membership function for which indicates the degree of membership that $\mathrm{x}$, of the universal set $\mathrm{X}$, belongs to set $\mathrm{A}$ and is, usually, expressed as a number between 0 and 1 .

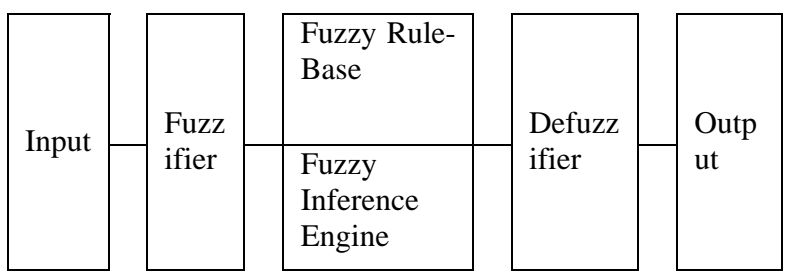

Figure 1. Diagram of fuzzy inference

Fuzzy theory has been applied to describe ambiguous data in many filed include engineering fields. Fuzzy set is used for fuzzy inference and the process of inference is introduced in Figure 1. After fuzzification of the input data, Fuzzy inference is done based on the fuzzy rule, then output comes through defuzzification of the inference values.

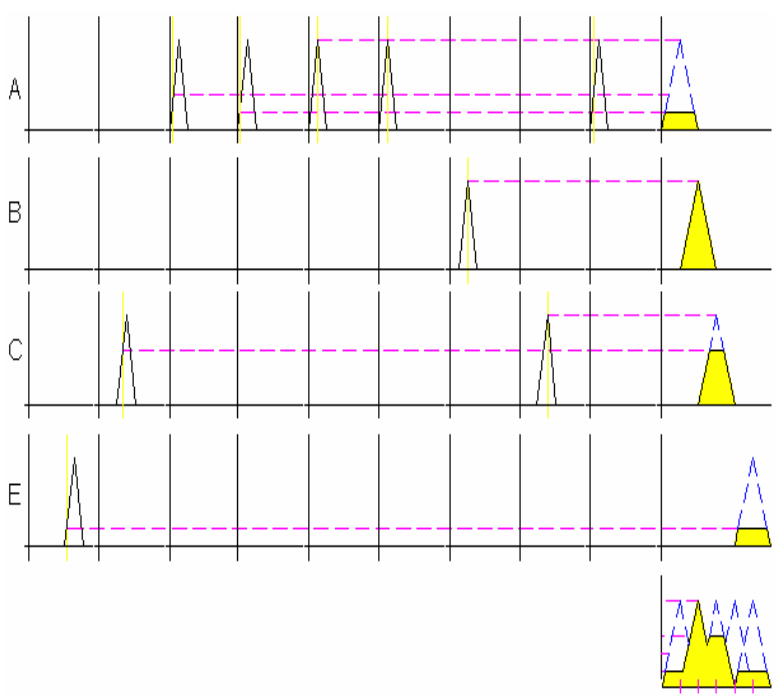

Figure 2. Fuzzy inference processing

Fuzzy reasoning needs fuzzy rule. If the rule, "IF $\mathrm{x}$ is A then $y$ is B" were given, $y$ is to be inferred with the condition of the input information, " $x$ is A". Fuzzy rule is expressed IF-THEN form and consists of precondition proposition and post-condition proposition.

\subsection{Tunnel face mapping $\mathrm{D} / \mathrm{B}$}

D/B for this expert system consists of 8 groups whose characteristics of tunnel construction is different. Table 1 shows explanation of each database group such as special ground condition or major concerning of tunneling. The standard of division is based on the major situation of tunneling in Korea.

Table 1. Tunnel face mapping information for $\mathrm{D} / \mathrm{B}$ 


\begin{tabular}{|l|l|l|l|}
\hline D/B & Site & No. of face & $\begin{array}{l}\text { Length } \\
(\mathrm{m})\end{array}$ \\
\hline Under river & River Han & 133 & 460 \\
\hline Fault zone & Pusan subway & 330 & 600 \\
\hline $\begin{array}{l}\text { Weathered } \\
\text { rock and sand } \\
\text { soil }\end{array}$ & $\begin{array}{l}\text { Seoul subway } \\
\text { station 6-00 }\end{array}$ & 97 & 200 \\
\hline $\begin{array}{l}\text { Seoul subway } \\
\text { station 6-00 }\end{array}$ & 60 & 50 \\
\hline $\begin{array}{l}\text { Weathered } \\
\text { rock }\end{array}$ & $\begin{array}{l}\text { Seoul subway } \\
\text { station 5-00 }\end{array}$ & 91 & 118 \\
\hline $\begin{array}{l}\text { Alluvial near } \\
\text { river }\end{array}$ & $\begin{array}{l}\text { Seoul subway } \\
\text { station 5-00 }\end{array}$ & 154 & 338 \\
\hline $\begin{array}{l}\text { Ground } \\
\text { Structure }\end{array}$ & $\begin{array}{l}\text { Seoul subway } \\
\text { station 5-00 }\end{array}$ & 59 & 106 \\
\hline $\begin{array}{l}\text { Underground } \\
\text { structure }\end{array}$ & $\begin{array}{l}\text { Seoul subway } \\
\text { station 5-00 }\end{array}$ & 67 & 436 \\
\hline $\begin{array}{l}\text { Fault zone \& } \\
\text { Gneiss }\end{array}$ & Road tunnel & 170 & 450 \\
\hline
\end{tabular}

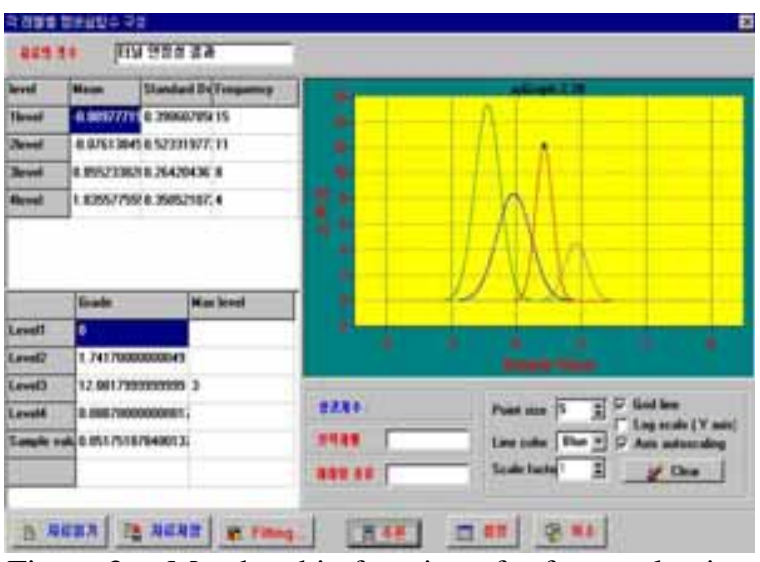

Figure 3. Membership function of safety evaluation of tunnel face

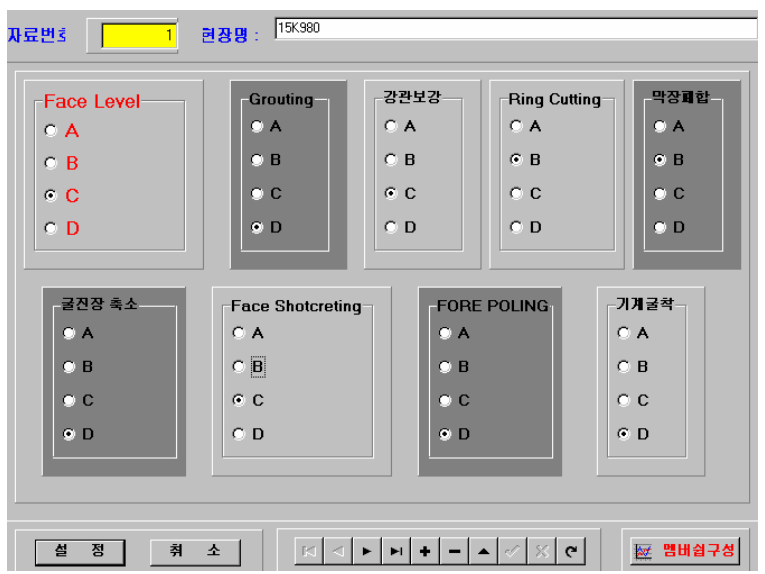

Figure 4. Tunnel Reinforcement database

is arranged between safety level and countermeasure method, then proper applicability of tunnel reinforcement is selected from post-module tunnel information database.

Tunnel information database consists of major face mapping items and tunnel safety effect factors such as adjacent building and overburden above tunnel, but in this system, only face mapping data expressed 4 levels was used. Main input data was made of uniaxial strength, RQD, joint spacing, joint condition, joint direction and water inflow included to RMR classification commonly adapted in Korea. First membership function built by correlation coefficient evaluates the safety level of tunnel face in Figure 3. Input module of tunnel reinforcement database showed in Figure 4 has eight items mostly used major collapsed sites and it consists of face shotcrete, ringcut excavation, mechanical excavation, forepoling, L.W grouting, bench shorten, invert and steel pipe grouting. As shown in Figure 5, membership for the applicability of each reinforcement method was built and the grade was calculated by defuzzification using centroid method. Fuzzy inference rule between each group of data and reinforcement methods shows in Table 2.

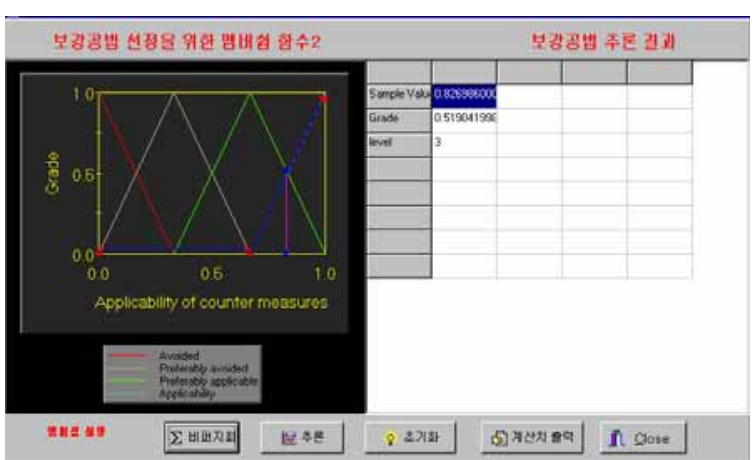

Figure 5. Membership function of reinforcement

Table 2. Fuzzy inference rule of Seoul subway

\begin{tabular}{|l|l|l|l|l|}
\hline No. of face & 1 & 2 & 3 & 4 \\
\hline \multicolumn{5}{|l|}{ First membership grade } \\
\hline Level A & 0.96 & 0.09 & 0 & 0 \\
\hline Level B & 0.04 & 0.91 & 0.98 & 0.01 \\
\hline Level C & 0 & 0 & 0.02 & 0.99 \\
\hline Level D & 0 & 0 & 0 & 0 \\
\hline
\end{tabular}




\begin{tabular}{|l|l|l|l|l|}
\hline \multicolumn{4}{|l|}{ Fuzzy inference rule } \\
\hline Face shocrete & 0.18 & 0.63 & 0.67 & 0.88 \\
\hline $\begin{array}{l}\text { Steel pipe } \\
\text { grouting }\end{array}$ & 0.67 & 0.67 & 0.67 & 0.88 \\
\hline Ringcut & 0.14 & 0.33 & 0.34 & 0.87 \\
\hline $\begin{array}{l}\text { Mechanical } \\
\text { excavation }\end{array}$ & 0.14 & 0.33 & 0.34 & 0.87 \\
\hline $\begin{array}{l}\text { L.W grouting } \\
\text { Invert }\end{array}$ & 0.35 & 0.74 & 0.86 & 0.12 \\
\hline Bench shorten & 0.18 & 0.63 & 0.67 & 0.88 \\
\hline Forepoling & 0.16 & 0.78 & 0.89 & 0.89 \\
\hline
\end{tabular}

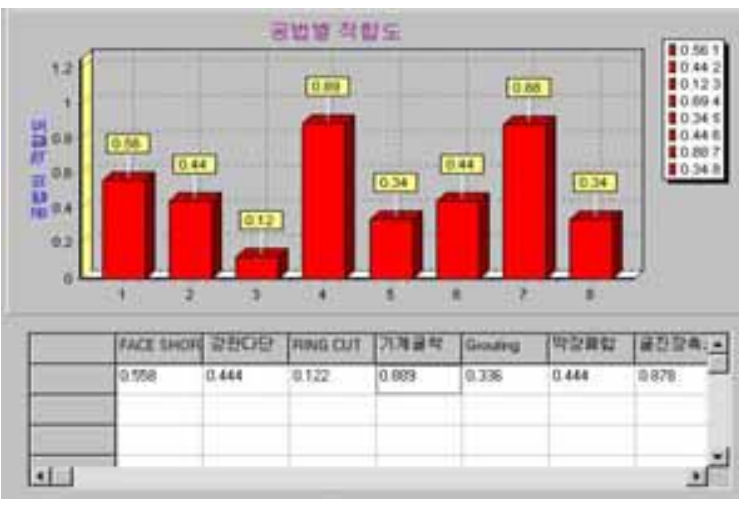

Figure 6. Inference result of reinforcement applicability

The comparison results between the predicted applicability by reinforcement system and measured data were very similar. In-situ data were obtained in eight tunnel sites as shown in Table 1. There is inference result of eight reinforcement methods used in Seoul subway tunnel in Figure 6. In the case of Seoul subway tunnel under the river Han, 104 sections were used for building database among 133 face mapping data, then the system was tested with other 29 sections. This system will be very helpful to make the most of in-situ data and suggest proper applicability of tunnel reinforcement system escaping from the dependence of some experienced experts for the absent of guide.

\subsection{Additional decision-making}

After evaluating the applicability of each reinforcement method by fuzzy inference system, user can be provided a simple pattern of selecting methods with more specific data of tunneling such as details of ground condition and occurring problems. Ground condition consists of seven items as shown in Table 3 and the levels were defined according to the opinion of experienced experts and construction results in Korea. Problems of excavation are composed of five items and each problem has countermeasure methods shown in Table 4. The relationship between each problem and its countermeasure is based on the Korea specification and opinions of experts. Table 5 shows the pattern of suggestion method for the given 2 input data.

Table 3. Details of ground condition

\begin{tabular}{|c|c|}
\hline Items & Level \\
\hline Depth & $\begin{array}{l}\text { less than 1.0D } \\
1.0-1.5 \mathrm{D} \\
1.5 \mathrm{D}-3 \mathrm{D} \\
\text { More than 3D }\end{array}$ \\
\hline Ground Classification & \begin{tabular}{|l} 
Sediment \\
Weathered soil \\
Weathered rock \\
Soft rock \\
Moderate rock \\
\end{tabular} \\
\hline Fault Zone & $\begin{array}{l}\text { Yes } \\
\text { No }\end{array}$ \\
\hline Location of Fault zone & $\begin{array}{l}\text { On the face } \\
\text { crown } \\
\text { lower than 0.5D } \\
0.5 \sim 1.5 \mathrm{D} \\
\text { higher than } 1.5 \mathrm{D}\end{array}$ \\
\hline Overburden & Calculation \\
\hline Inflow & \begin{tabular}{|l} 
Dry \\
$(10 \sim 25 \ell / \mathrm{min})$ \\
$(25 \sim 125 \ell / \mathrm{min})$ \\
$(>125 \ell / \mathrm{min})$
\end{tabular} \\
\hline Location of Groundwater & Over SL, Below SL \\
\hline
\end{tabular}

Expert system will provide construction site direct countermeasure method for the unexpected problems via on-line. Selecting similar ground condition among the 8 data group, Proper reinforcement is suggested and similar construction pattern, which was used in other sits, will be very helpful in decision-making.

Table 4. Problems of excavation

\begin{tabular}{|c|c|c|}
\hline Items & Level & Countermeasure \\
\hline Overburden & $\begin{array}{l}<1.0 \mathrm{D} \\
1.0-1.5 \mathrm{D} \\
1.5 \mathrm{D}-3 \mathrm{D} \\
>3 \mathrm{D}\end{array}$ & $\begin{array}{l}\text { Forepoling, } \\
\text { Umbrella arch, } \\
\text { Ringcut, } \\
\text { Jet grouting, } \\
\text { Piperoof }\end{array}$ \\
\hline Inflow & RMR & Chemical grouting \\
\hline $\begin{array}{l}\text { Face } \\
\text { stability }\end{array}$ & Fuzzy level & $\begin{array}{l}\text { Face shotcret, } \\
\text { invert, ringcut, } \\
\text { bench shoten, } \\
\text { Face rockbolt }\end{array}$ \\
\hline $\begin{array}{l}\text { Adjacent } \\
\text { Building }\end{array}$ & $\begin{array}{l}\text { On the face } \\
\text { crown } \\
<0.5 \mathrm{D} \\
0.5 \sim 1.5 \mathrm{D} \\
>1.5 \mathrm{D}\end{array}$ & $\begin{array}{l}\text { Piperoof, } \\
\text { forepoling, } \\
\text { umbrella arch method, } \\
\text { Jet grouting }\end{array}$ \\
\hline $\begin{array}{l}\text { Surface } \\
\text { settlement }\end{array}$ & $\begin{array}{l}\text { Neural network } \\
\text { inference }\end{array}$ & $\begin{array}{l}\text { Piperoof, } \\
\text { Jet grouting, } \\
\text { umbrella arch method, } \\
\text { Invert }\end{array}$ \\
\hline
\end{tabular}


Table 5. Suggested pattern of reinforcement

\begin{tabular}{|l|l|}
\hline Method & Forepoling \\
\hline Purpose & $\begin{array}{l}\text { Sealing of fault zone and } \\
\text { reinforcement of around tunnel face }\end{array}$ \\
\hline Design Pattern & $\begin{array}{l}\mathrm{L}=12 \mathrm{~m} \\
2 \text { colums overlab }\end{array}$ \\
\hline Others & More than 5 hole into the tunnel face \\
\hline Warning & $\begin{array}{l}\text { If upper alluvial layer comes close to } \\
1 \text { m, reinforcement required }\end{array}$ \\
\hline
\end{tabular}

The data used in this study were obtained form the various tunnel construction sites in South Korea. They consisted of laboratory tests and engineering rock mass classification. They are specific gravity, absorption ratio, $\mathrm{P}$ and $\mathrm{S}$ wave velocities, uniaxial compressive strength, elastic modulus, Poisson's ratio of intact rock, tensile strength, cohesion and friction angle by triaxial compressive test in the laboratory test. They also include RMR and Q values. It is possible to have different influences on rock mass properties even in the same RMR values with the different combinations of six RMR ratings. So separate ratings except for adjustment according to joint orientation were included as input variables for fuzzy model. And output variables were deformation modulus, cohesion and friction angle widely used in numerical analysis. These input and output variables are tabulated in Table 1.

\subsection{Training and validation data}

A total number of 107 data obtained from the domestic tunnel construction sites were randomly divided into four sets of $25 \%$ of total data. And each set had 26 or 27 records $(27+27+27+26=107)$. The three sets (75\%) were used for training of fuzzy model and the other set (25\%) was used for validation of it, which meant that there were four possible fuzzy models in each prediction of engineering rock mass property. The reason for doing this was to see how much variation there were in accordance with the distributions of training and validation data. The names of fuzzy models are tabulated in Table 2. Also the data used here was scaled between 0 and 1 , which reduced the time for calculation and effect induced by different measured units in each parameter.

\subsection{Criteria for the selection of model}

Modified TS fuzzy models were trained until they satisfied the criteria as increasing the number of clusters of input data. The indices used for the criteria were RMSE (Root Mean Squared Error) and the rate. Rate is the change of RMSE in each training stage defined by Chen (1998) shown below.
Table 3. Input (X) and output (Y) parameters and their ranges for fuzzy model.

\begin{tabular}{lll}
\hline & Parameters & Range \\
\hline X1 & Specific gravity (\%) & $0-5$ \\
X2 & Absorption ratio (\%) & $0-12$ \\
X3 & P-wave velocity (m/s) & $0-8000$ \\
X4 & S-wave velocity (m/s) & $0-5000$ \\
X5 & Uniaxial compressive strength (MPa) & $0-500$ \\
X6 & Elastic modulus (GPa) & $0-20$ \\
X7 & Poisson's ratio & $0-0.5$ \\
X8 & Tensile strength (MPa) & $0-50$ \\
X9 & Cohesion (MPa) & $0-50$ \\
X10 & Friction angle (Deg) & $0-90$ \\
X11 & RQD & $0-100$ \\
X12 & RMR-1 (uniaxial compressive strength) & $0-15$ \\
X13 & RMR-2 (RQD) & $0-20$ \\
X14 & RMR-3 (spacing of discontinuities) & $0-20$ \\
X15 & RMR-4 (condition of discontinuities) & $0-30$ \\
X16 & RMR-5 (ground water) & $0-15$ \\
X17 & RMR & $0-100$ \\
X18 & Q & $0-1000$ \\
\hline Y1 & Deformation modulus (GPa) & $0-30$ \\
Y2 & Cohesion (MPa) & $0-20$ \\
Y3 & Friction angle (Deg) & $0-90$ \\
\hline
\end{tabular}

$$
\begin{aligned}
& \text { RMSE }=\sqrt{\frac{1}{n} \sum_{k=1}^{n}\left(y_{k}-\hat{y}_{k}\right)^{2}} \\
& \text { Rate }=\frac{|R M S E-R M S E(0)|}{R M S E}
\end{aligned}
$$

\section{Inference Results}

Based on the tunnel face mapping database, relationship and partial relationship between face stability and RMR factors were analyzed. Partial relationship coefficient means the strength of effectiveness of each factor to face stability when other items are fixed. Relationship coefficient between face stability and RMR items of 8 database groups is shown in Figure 7 and there are various differences among the groups of data according to property of construction situation.

As shown in Figure 8, partial relationship coefficients of 8 data groups between face stability and RMR items are various and it means that major effective factor of face stability is not same in all tunnels. In the same way, the relationship between face stability and the applicability of reinforcement methods was analyzed. Relationship coefficient shows that appropriate reinforcement methods should be considered differently according to the group of data because each database has different property of ground or construction problem. It means that each tunneling face needs different countermeasure method depending on the property of tunneling situation and problem. 


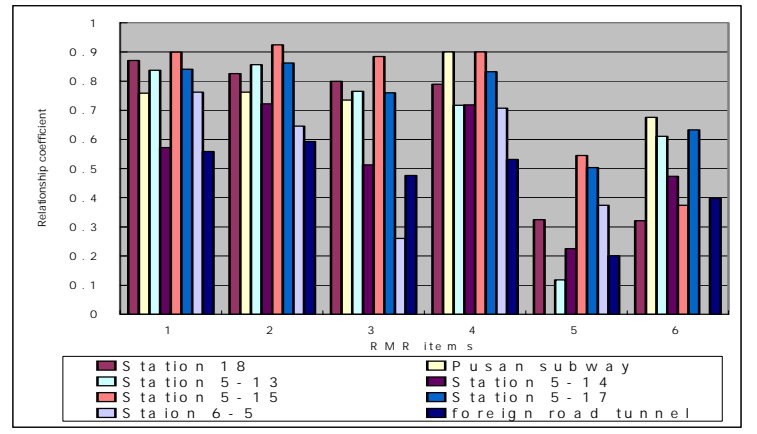

Figure 7. Relationship coeficient between face stabili ty and RMR items

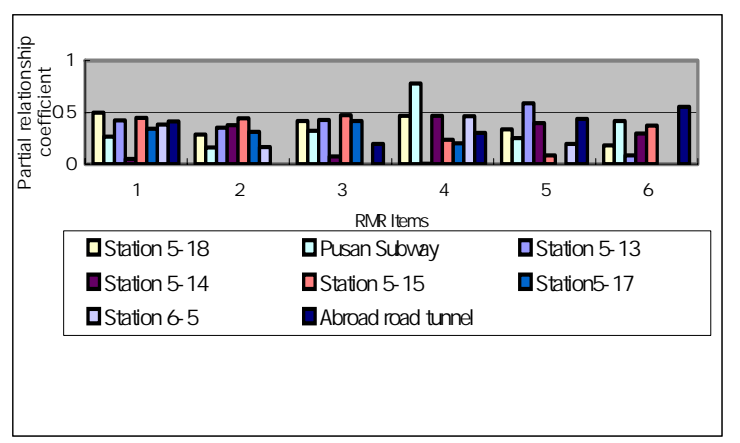

Figure 8. Partial relationship coefficient between face stability and RMR items

\section{Conclusions}

In this study, after tunnel collapsed incidents were surveyed and the detail causes were analyzed, the expert system for tunnel reinforcement selection was presented. Database is divided to 8 different data group according to the properties of tunneling construction and major problem of excavation because each data group provides different inference results from each particular condition. From this the following suggestions were made for better understanding of the tunnel reinforcement system.

Prototype of the expert system was developed to evaluate of tunnel safety and select proper reinforcement method based on the fuzzy theory after building tunnel information Database.

The expert system developed in this study has been tested on 8 in-situ sites including the river Han subway tunnel considered one of the most difficult construction sites and needed various reinforcement methods. Its applicability has been confirmed by comparison of inferred results and field data.

There are some different among the correlation coefficients between RMR factors, which used as tunnel face observation items, and tunnel safety level according to the in-situ sites. Partial correlation coefficients are various as well. It verified that face mapping items may be considered differently at each site.

\section{ACKNOWLEDGMENT}

This research has been performed as a part of the National Research Laboratory project provided by KMOST (Korea Ministry of Science \& Technology) and Samsung Construction Co.. The authors greatly appreciate their financial support.

\section{REFERENCES:}

[1] Ghaboussi J, Pecknold D.A., Zhang M, Haj-ali R.M., "Autoprogressive training of neural network constitutive models”, Int. J. Numer. Meth. Engng, Vol. 42, pp. 105-126, 1998.

[2] Kim, C.Y., Park, C.H., Bae, G.J., Hong, S.W. \& Oh, M.R., 2001, Countermeasure Expert System for Tunneling Failure, AITES-ITA 2001, pp. 409-416

[3] Chikahisa, H., Matsumoto, K., Nakahara, H. \& Tsutsui, M., 1997, Measurement Control Method and Expert System for Tunneling by Fuzzy Set Theory, Environmental and Safety Concerns in Underground Construction, pp. 261-266

[4] Fairhurst, C. and Lin, D., 1985, Fuzzy Methodology in Tunnel Support Design in Research and Engineering Applications in Rock Masses (ed. Ashworth, E.), Proc. 26th U.S. Rock Mechanics Symposium, Accord MA: International Publishers Service Inc., pp.269 278

[5] HSE, 1996, Safety of New Austrian Tunnelling Method (NATM) Tunnel, 15-28

[6] Park, K.J. and Lee, I.K., 1993, Modes and Causes of Collapse of Subway Tunnels, Proceeding of National Conference of Geotechnical Engineering and Tunnelling Technology, Seoul Korea, pp. 41 48

[7] Watada, J., H. Tanaka \& K.Asai, 1982, Fuzzy Quantification theory type II. J. Measurement of Action, 9(2), pp.24 32

[8] Wamagata, S., Chikahisa, H., Kurosaka, S., Arai, Y. \& Nakahara, H., 1989, Development of measurement control system for tunneling. Tobishima Eng. Report, 40, pp.103 1171 